\title{
BEHAVIOUR OF 3D-PANELS FOR STRUCTURAL APPLICATIONS UNDER GENERAL LOADING: A STATE-OF-THE-ART
}

\author{
P. Poluraju', G. Appa Rao ${ }^{2}$ \\ ${ }^{1}$ PhD Scholar, Department of Civil Engineering, Indian Institute of Technology Madras, Chennai-600036, India \\ ${ }^{2}$ Professor, Department of Civil Engineering, Indian Institute of Technology Madras, Chennai-600036, India
}

\begin{abstract}
This paper reports on a comprehensive review of state of art on the performance of $3 D$ panels for structural applications under general loading. Axial compression strength of $3 D$ wall panel depends on compressive strength of concrete and aspect ratio of the wall panel, whereas shear strength of 3D panels depends on the number of diagonals (100 or 200 diagonals per sq.m). The flexural strength of 3D slab panels depends on shear span and degree of composite action. The seismic performance of buildings using 3D panels is well understood that forces acting horizontally on 3D panel buildings, due to earthquake forces, are transferred most effectively by $3 D$ shear walls. A frame-like design of $3 D$ buildings with heavy reinforcement in the joints is not necessary. Especially in residential buildings a box-like 3D-structure is the best option to receive high strength and meet architectural requirements at the same time. For dimensioning, 3D slabs and $3 D$ walls can be considered independently of each other.
\end{abstract}

Keywords: 3D Panel, Truss Steel Connector, Axial compression load, Monotonic load, cyclic load ****

\section{INTRODUCTION}

Housing remains a big challenge for Civil Engineers and many governments, especially in the developing countries of the world. The problem is aggravated by fast increasing population, migration of rural masses into the urban and industrial centres, which demands for better quality of life. It is tough task to meet this challenge with traditional building construction practices, as it is essential to meet the housing demand in a short duration without sacrificing the quality. Due to this inadequacy of traditional building construction systems, new building systems appeared at the beginning of the $20^{\text {th }}$ century. Industrialized Building Systems (IBS), defined as the building systems in which components, prefabricated at site or in a factory and then assembled to form a complete structure with minimum in-situ construction, are destined to provide a solution to this multidimensional problem, especially since the buildings constructed using this alternative method of construction have a shorter construction time with the additional advantages of strength, integrity, durability, indoor thermal comfort and labour saving (Benayoune et al. 2004). 3D wire panel (3D panel) is a prefabricated panel, which consists of a super-insulated core of rigid expanded polystyrene sandwiched between two-engineered sheets of $2.5 \mathrm{~mm}$ diameter $(\varnothing)$ with a tensile strength of $880 \mathrm{~N} / \mathrm{mm}^{2}$ steel welded wire fabric mesh. To achieve 3D panel form, another $2.5 \mathrm{~mm}$ diameter galvanized steel truss wire is pierced completely through the polystyrene core at offset angles for superior strength and integrity, and welded to each of the outer layer sheets of eleven-gauge steel welded wire fabric mesh. The 3D wire mesh panels are used for numerous building applications including floor systems, ceilings and a roof structure. The 3D panel is an excellent product for building privacy walls around the home or building structure (EVG). Fig. 1. demonstrates typical 3D panel with steel connectors.

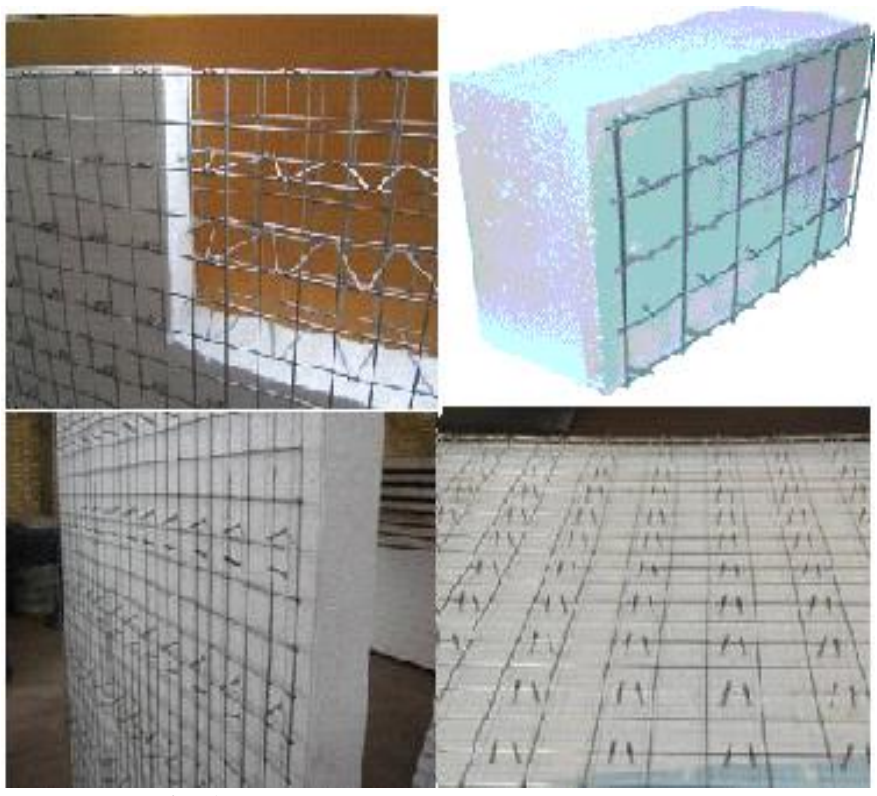

Fig.1. 3D Wire Panel (currently in use).

\subsection{Components of Installed Panel:}

a) EPS core for insulation

b) Wire mesh on inside and outside

c) Welded truss of wire cross pieces

d) Sprayed concrete on both sides (shotcrete) or manual concreting

These panels are 4 feet wide and can be produced in almost any length. They can be used for the walls and roof as shown in Fig. 2. 


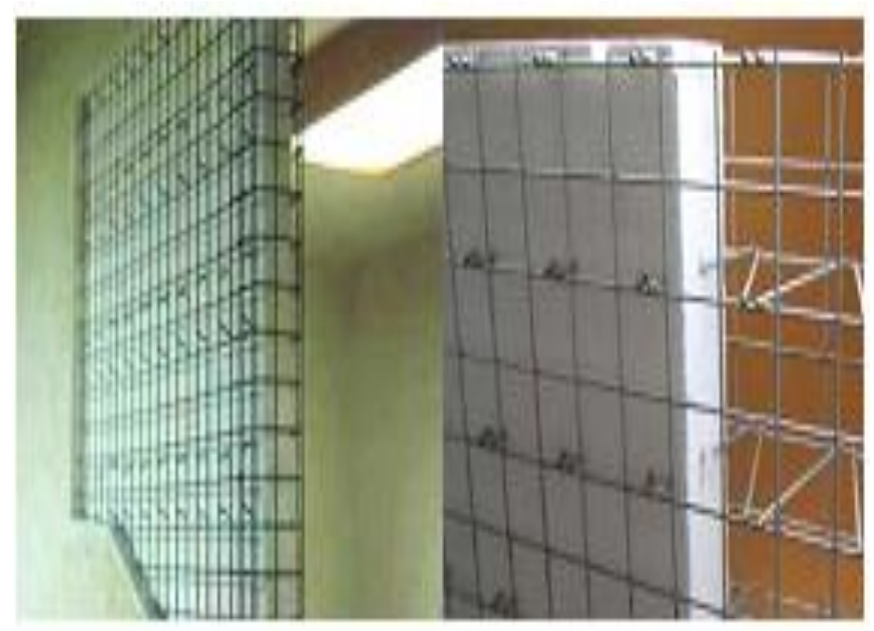

Fig. 2. Typical 3D wall panel (Skeleton)

\subsection{Applications}

3D Panel is placed in position and layer of concrete or mortar are applied to both sides. This is shown in Fig. 3. 3D wall panels are used in the construction of exterior and interior bearing and non-load bearing walls and floors in all types of construction. The wall panel receives its strength and rigidity from the diagonal cross wires welded to the welded-wire fabric on each side. This combination creates a truss behaviour, which provides rigidity and shear terms for full composite behaviour (EVG).

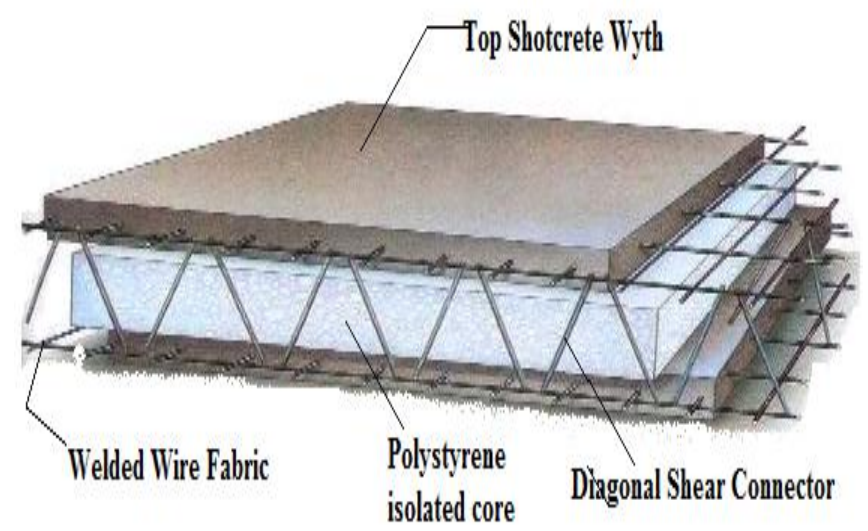

Fig. 3 3D Sandwich panel (Kabir et al. 2005)

The 3D panel cover mesh can also serve as bottom or top reinforcement of floor slabs. This reinforcement is sufficient for spans of up to approximately $3.0 \mathrm{~m}$. Additional rebars can be arranged for spans of up to approximately $5.0 \mathrm{~m}$. Slabs with spans exceeding $5.0 \mathrm{~m}$ must be provided with ribs which are reinforced with truss girders and additional rebars.

\subsection{Background}

In general, sandwich panels behave similarly to other present concrete members. However, due to the presence of the interventing wythe of insulation, sandwich panels do exhibit some unique characteristics and behaviour. Present knowledge of the behaviour of sandwich panels is based on observed field performance and limited laboratory testing. As a result, there is a lack of agreement among designers concerning degree of composite action and resulting panel performance. Much of the present understanding about the behaviour and design of sandwich panels is presented in two recent past reports. The first report, by Einea, Salmon, Fogarasi, Culp, and Tadros, titled "State-of-the Art of Precast Sandwich Wall Panels," was published in 1991. The second report, by the PCI Committee on Precast Sandwich Wall Panels, titled "State-of-the Art of Precast/ Prestressed Sandwich Wall Panel" (hereafter referred to as the PCI State-of-the-Art Report), was published in 1997.

\subsection{Composite, Non-Composite, and Partially}

\section{Composite Panels}

Fully composite panel: A panel is considered fully composite when the two concrete wythes act like a single unit, and this is achieved by providing enough shear connectors between the two wythes. In this case, connectors are transferring required longitudinal shear so that the strain and bending stress distribution remains linear across the panel thickness as shown in Fig.4 (a)

Semi-composite panel: A panel is considered semicomposite when shear connectors transfer only a fraction of the longitudinal shear as required for a fully composite panel. This fraction could range from zero to one hundred percent of the total longitudinal shear required for fully composite action. Note that quantifying the composite action in PCSP is based on experience and engineering judgement. The strain and bending stress distribution for a partially composite panel is shown in Fig.4 (b)

Non-composite panel: In this special case, shear connectors do not have enough capacity to transfer longitudinal shear, and as a result, the two wythes act independently. In some cases, both concrete wythes have same stiffness and reinforcement; therefore, each wythe resists half of the applied load. However, in most cases, only one wythe called the structural wythe will resist the total load. The stress and strain distributions for the former and case are shown in Fig 4(c) and 4(d), respectively. 


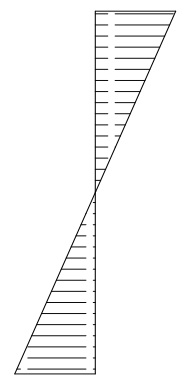

(a) Fully composite

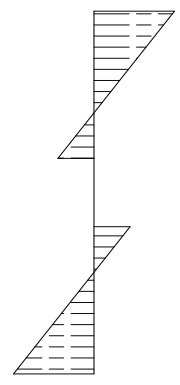

(b) partially composite

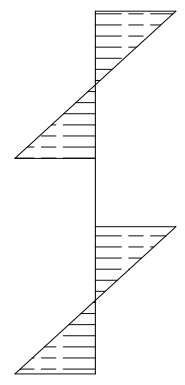

(c) Non-composite,

Two structural wythe

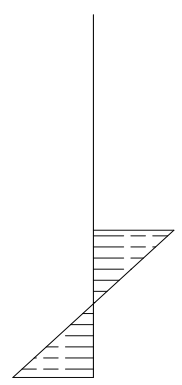

(d) Non-composite,

One structural wythe

Fig.4. Stress and strain distribution in 3D panels under flexure

\subsection{Constituents of Sandwich Panels}

\subsubsection{Concrete Wythes}

The thickness of each concrete wythe depends on its structural function, concrete cover, anchorage of connectors, stripping, and finish. Although some publications (PCI Design Handbook, 1985) provide guidelines for the thickness of wythes, each 3D producer has determined appropriate thickness for their own practice. The concrete wythes can be divided into structural wythes and nonstructural wythes.

1.5.1(a). Structural wythe: A wythe is considered structural if it provides a significant contribution to the load resistance of the panel. In fully or partially composite panels, both concrete wythes are structural. In non-composite panels, either one of the wythes is structural and the other is nonstructural, or both wythes are structural and independently resist the applied loads in proportion to their relative stiffnesses. Although the minimum recommended thickness of structural wythe is 2 in. (50 mm) if prestressed and 3 in. (76 mm) if non-prestressed (Architectural PCI, 1989) a thickness as small as $3 / 4$ in. (19 mm) has been used (Insteel Construction Systems, Inc., Brunswick, GA).

\subsubsection{Insulation}

The thickness and type of insulation depends on the thermal properties of the insulation material used, the design temperature of the structure and the desired thermal resistance of the panel. Generally, a minimum thickness of 1 in. $(25 \mathrm{~mm})$ is used. The insulation should have low absorption to minimize the loss of water from the freshly placed concrete (Einea et al. 1991).

1.5.2(a). Expanded polystyrene (EPS): This material is formed by either a molding or an extrusion process. In the molding process, tiny polystyrene beads are impregnated with a blowing agent, typically pentane. The beads are then exposed to pressurized steam, causing the blowing agent to vaporize and thereby partially expanding the beads. They are then placed in large molds and exposed to pressurized steam, causing them to fully expand and fuse together to form a solid piece called a billet. The billet can then be cut into boards (Einea et al. 1991). Figure 5 shows, schematically, the 3D panel cross section.

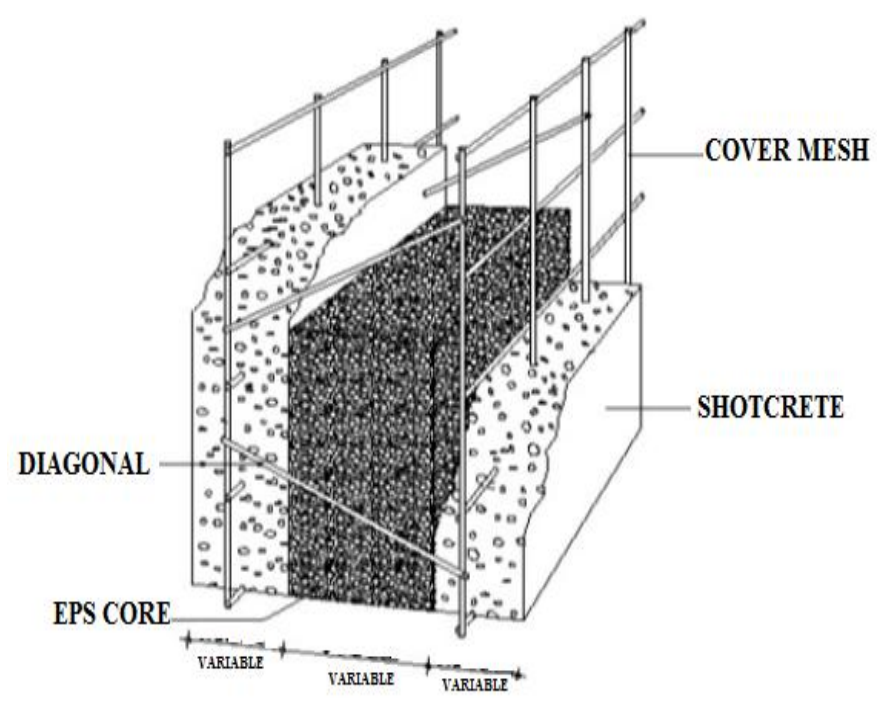

Fig.5. 3-D Cross Section (EVG)

\subsection{D Concrete Sandwich Panel as Wall}

3D Panel was examined for its structural performance, as measured by load/deflection behaviour, strain distribution across the thickness of the panel and efficiency of shear connectors and their role in transferring loads from one wythe to the other as well as in ensuring the overall stability of the panel. The influence of wall slenderness ratio on the ultimate strength of the panels was investigated by varying the height of the walls. As the concrete wythes were relatively thin, they were susceptible to buckling especially when the shear connectors did not possess sufficient rigidity for composite action of the panel. Equation adopted by ACI equation and expressions proposed by various researchers developed for RC wall strength designs were used to analyse the 3D Panel. It was concluded that the 3D Panel can be used safely for low-rise building as their ultimate strength under axial and eccentric loads was at least four times greater than that required to withstand typical 5-storey ultimate design loads. The ultimate strength of the 3D Panel was found comparable to the strength for full composite 
panels. The panels achieved a high composite behaviour at service and acted in partially composite manner at the ultimate stage. The ultimate load was found to decrease with an increase in slenderness ratio $(\mathrm{H} / \mathrm{t})$. The strength of the precast reinforced concrete sandwich panels was found to be governed by either material failure through crushing or buckling. The buckling load could be lower than the crushing load if the shear connectors did not have sufficient rigidity leading to premature failure. The buckling strength was affected significantly by the slenderness ratio (Benayoune et al. 2004).

\subsection{D Concrete Sandwich Panel as Slab}

The investigation was extended to explore the feasibility of 3D Panel as slab. Many issues related to flexural behaviour and design of 3D Panel such as stress estimation in both concrete wythes, composite action desired and prediction of the forces in shear connectors were addressed. A parametric study was carried out to study the influence of shear the number of connectors on the ultimate strength and the compositeness of the 3D Panel working as slab. The investigation included a study of strain distribution, degree of composite action at ultimate and elastic stages of the 3D Panel, their ultimate strength capacities, load-deflection profiles, and load-stress relationships. A method for the determination of the interface shear force, required for the design of shear truss-shaped connectors was presented. Different aspect ratios of slabs were also chosen to study the effect of the placement and the orientation of shear connectors on the behaviour of 3D Panel (Benayoune et al. 2004).

\section{BEHAVIOUR OF 3D WALL PANEL UNDER} AXIAL COMPRESSION LOADING

Benayoune et al. (2004) was carried out numerous compressive strength tests with wall structures manufactured with 3D construction method, have verified that the acknowledgement rules of reinforced concrete engineering also fully apply to the 3D sandwich building technique. Therefore, structural calculations of 3D constructions shall be made in accordance with the reinforced concrete strength design principles. As regards compression tests, wall panels with different internal layer thickness and with two different configurations were tested. High ultimate loads, decreasing for increasing values of the slenderness ratios, were obtained. Additional investigations are needed to develop simple, effective and rational methods for predicting the ultimate load of wall panels and to study the behaviour of panels without reinforced concrete beams (Gara et al. 2012).

Benayoune et al. (2007) have reported that, performances of 3D panels with slenderness ratio varying from 10 to 20 subjected to axial load ultimately fail by crushing. The load bearing capacity of the panels was found to decrease nonlinearly with the increase in the slenderness ratio. A comparison between the ultimate axial loads as determined using conventional approach based on reinforced concrete principles. The ultimate axial load decreases by increasing the panel slenderness ratio, defined $H / t$, where $H$ is the total height and $t$ the overall thickness of the panel, as shown in Fig. 6.

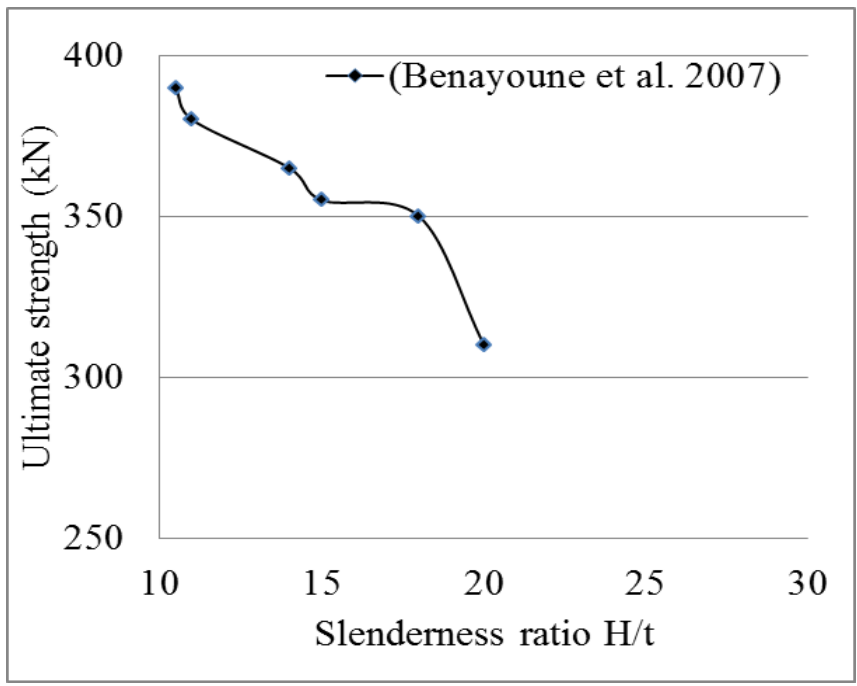

Fig. 6 Influence of panel slenderness ratio on axial ultimate loads (300 $\mathrm{mm}$ width wall)

Benayoune et al. (2006) in their experimental studies reveals that violent failure occurred in all cases of panel by crushing at either one or both ends of the panels. Inclined cracks near the edges in addition to crushing. Horizontal cracks were also observed in this panel near the top as shown in Figure 7. These cracks may be attributed to the instability of the panel. The panels were found to behave almost fully composite till failure as only a small discontinuity of strain was observed across the insulation layer, showing adequacy of the shear connectors. The design method for solid walls recommended by ACI equation and expressions proposed by other researchers was found to be very conservative as compared to FEA results.

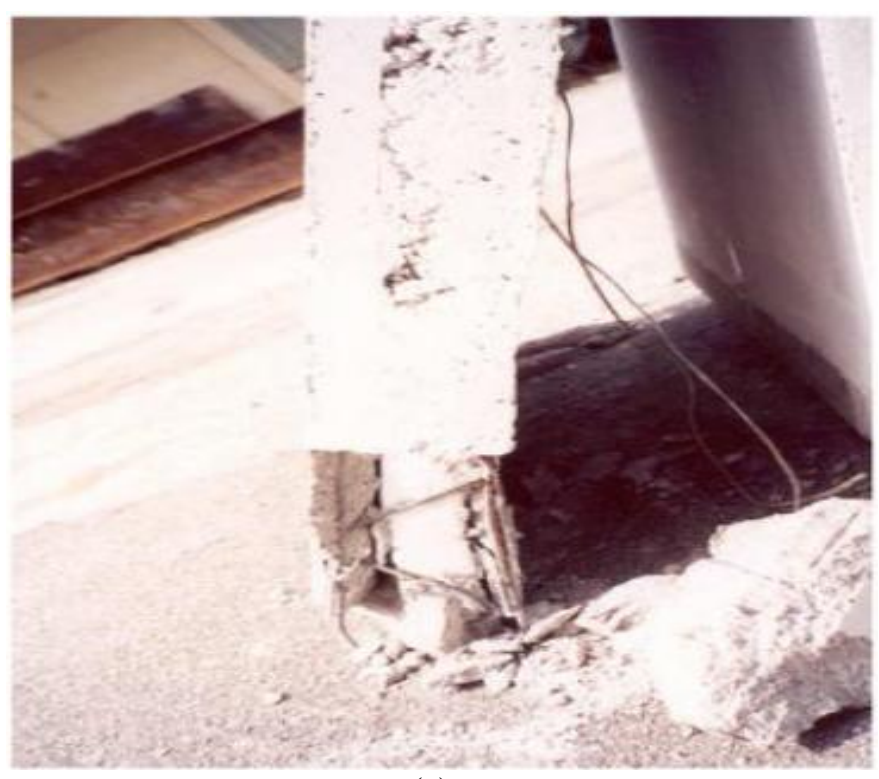

(a) 


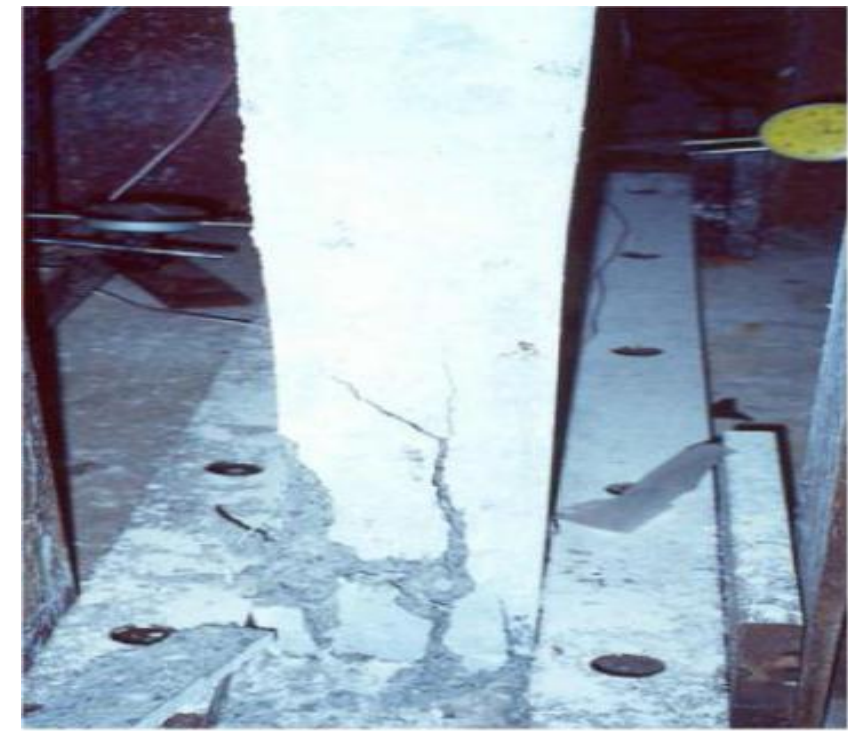

(b)

Fig. 7 Crushing at the (a) top and (b) bottom of the panel

Carbonari et al. (2013) have conducted experimental program on small-scale and slender panels to understand the behaviour of 3D panels. Despite the limited number of tests and repetitions in some cases, the results indicate that the compressive strength of the mortar and the thickness of the panel are the main aspects that affect the maximum load resisted by the panels. Such load increases with the increase of the compressive strength and with the reduction of the panel thickness. All these observations are in good agreement with the results estimated with the analytical formulation. Pillai and Parthasarathy (1977) have reported their experimental results revealed that reinforced concrete bearing walls with all the reinforcement placed in one layer at mid-thickness and carrying reasonably concentric loading, the present design procedures based on column theory as well as empirical design formula are very conservative. For such walls, the steel ratio has little influence on the ultimate strength. The ultimate strength of the wall panel decreases linearly with increase in aspect ratio. The ultimate strength of the wall panel decreases nonlinearly with increase in slenderness ratio. The ultimate strength of the wall panel increases almost linearly, with increase in vertical steel. The effect of horizontal steel on the ultimate strength of wall panel is negligible (Sahed and Prakash 1989). A substantial increase in wall capacity can be obtained only if the amount of vertical reinforcement is of the order of 0.75 to 1.0 percent of the gross cross-sectional area of the wall (Kripanarayanan, 1977). According to Garold et al. (1977) analysis of the code's empirical equation for wall design predicts ultimate loads considerably lower than failure loads for small $\frac{1}{h}$ values ( 8 to 12 ). Any fixity of the end restraints of the test walls would increase failure loads above the values obtained from the test program.

Fragomeni et al. (1994) have reported that the majority of investigations undertaken so far have focused on improving the empirical formula by using typical test conditions. Most have been based on walls supported top and bottom, slenderness ratios of 30 or under, minimum steel ratios, and concrete strengths between 20 to $35 \mathrm{MPa}$. These empirical wall design formulas have been applied extensively over the years. Further improvements may be made to these simplified formulas through the incorporation of other variables, such as the contribution of aspect ratios, steel contribution, and effects of high-strength concrete. Fragomeni et al. (2012) have conducted an experimental campaign on reinforced concrete walls. Half-scale specimens had high slenderness ratios between 30 and 40 . The test results indicate that failure loads and crack patterns depend on the support conditions. Further the axial strength ratio for panels gradually decreases when slenderness ratios are increased from 30 to 40 . This is clearly not the case as test results indicate significant capacities can be achieved. According to Mohamad et al. (2011) the ultimate failure load of wall panel was found to be influenced by the material's strength. The ultimate load increased with the increased in panels characteristic strength. The slenderness ratio was found to have a significant effect on the deflection measurements. The theoretical ultimate loads were calculated using (Sahed and Prakash, 1990) equation for ordinary reinforced concrete wall. The calculations were made with an assumption that the total thickness of the sandwich panel is equal to the total thickness of the two reinforced concrete layers only. After analysing the experimental data, the average ratios of experimental to theoretical ultimate loads for sandwich panels were found to vary between 0.99 and 1.01 . This shows that the ultimate load equation for ordinary reinforced concrete wall proposed by (Sahed and Prakash, 1990) can be used to estimate the ultimate load of precast concrete sandwich wall panels (Aziz et al. 2004). Some of the problems of precast concrete wall panels can be minimized if the architect, engineer, and precast industry realize that good service performance of precast concrete wall panels is possible. Through exchange of design, experience, and research. By designing ceiling, floor, and partition joints which intersect precast wall panels to allow a predetermined amount of lateral panel movement without developing unsightly cracks due to temperature and moisture differentials. By recognizing that the sandwich type precast panels are more susceptible to bulging than solid panels. By using smaller panels to keep lateral movement within acceptable tolerance. Through the use of lightweight structural concrete or foamed concrete which has a smaller coefficient of expansion than regular concrete (Leabu et al. 1959).

\section{BEHAVIOUR OF 3D WALL PANEL UNDER} IN-PLANE LATERAL LOADING

Pavese et al. (2011) performed seismic tests on single fullscale wall with or without openings which were tested as cantilever or with fixed ends, and on a 2-storey full-scale $\mathrm{H}$ shaped structure constructed by individual panels which were properly joined together. All panels tested herein revealed strong coupling between flexure and shear since under seismic loading, these squat type geometry panels, are subjected to in-plane shear and axial stresses (membrane elements). However brittle failure owing to diagonal tension 
was controlled due to the well-detailed steel reinforcement. The response of the $\mathrm{H}$-shaped structure was dominated by shear cracking on the web and by flexural yielding of the flanges. Hamid (2008) in her experimental study reveals that, monolithic wall panel experiences a substantial structural damage when tested under quasi-static lateral cyclic. The structural damage were wall cracks, spalling of concrete and fractured of longitudinal reinforcement bars at both bottom corner of the wall. Precast wall performed better than monolithic wall in terms of damage index, ductility, and strength. The experimental result shows very similar and good agreement with theoretical results. The theoretical backbone gives a relatively close approximation to the measured response, suggesting only a slightly greater capacity at the higher drift levels. The performance of the specimen was close to that predicted analytically. The graph also shows a typical behaviour characteristic of a conventionally monolithic reinforced concrete structural wall. Energy was dissipated mainly through yielding of the longitudinal wall reinforcement at the plastic hinge region. The connection of the wall to the foundation beam had no influence on the overall response of the unit. Adequate detailing of reinforcement bars at plastic hinge zone which located at one-fifth from wall panel to deform in a ductile manner as clearly shown in Fig. 8.

\section{Full hysteretic Response}

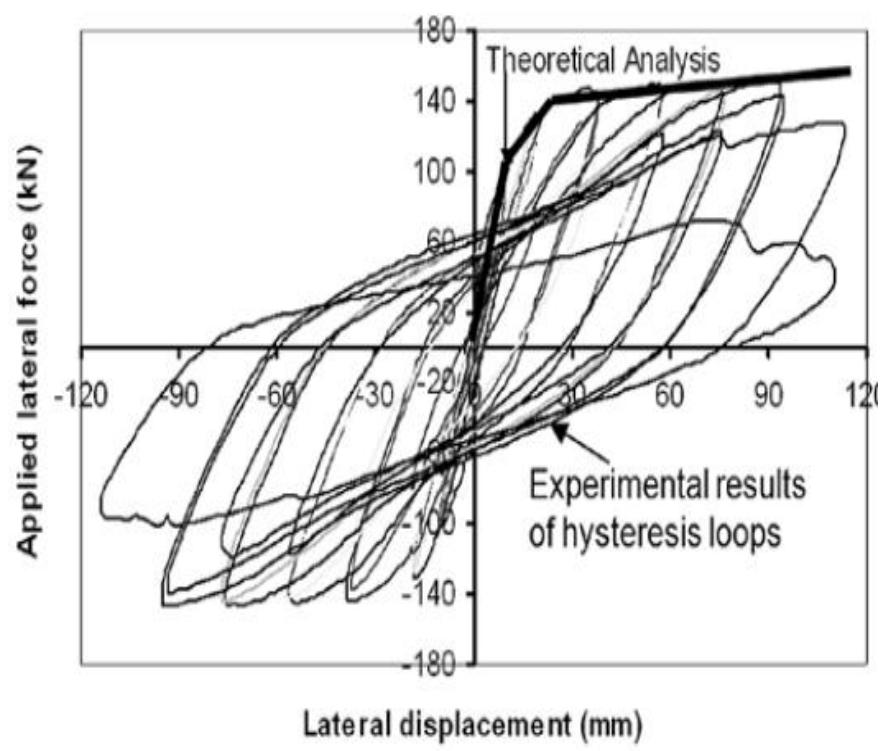

Fig. 8 Hysteretic response of wall under in-plane loading

Frankl et al. (2011) tested wall panels, were subjected to monotonic axial and reverse-cyclic lateral loading to simulate gravity and wind pressure loads, respectively. It was concluded that Panel stiffness and deflections are significantly affected by the type and configuration of the shear transfer mechanism. Panel stiffness is also affected by the type of foam. For a given shear transfer mechanism, a higher percent composite action can be achieved using EPS (Expanded polystyrene) insulation rather than XPS insulation. Use of XPS (Extruded polystyrene) insulation requires an increase of the shear reinforcement ratio compared with EPS insulation. Khare et al. (2011) reviewed on seismic performance and behaviour of precast concrete structures. It was indicated that the buildings constructed and designed incorporating seismic design concepts performed remarkably well. Also concluded that the provisions in IS 11447: 1985 for seismic design of large panel prefab buildings are insufficient in general and from the earthquake resistant point of view. It is recommended to include a chapter on general provisions on precast concrete element and structures in IS 456: 2000 and special provisions on seismic design of precast concrete elements and structures in IS 13920: 1993. Need of experimental investigation, is also felt to study the seismic performance of the structural element in Indian environment. Based on the experimental investigations and experiences on seismic performance a state-of-the art report can be prepared for the analysis and design of precast concrete structures in the country.

Behaviour of prefabricated RCSPs (Reinforced Concrete Sandwich Panels) under simulated seismic loading through a large experimental campaign. Tests were carried out on single full-scale panels. From the results obtained in this study, the presented structural systems with prefabricated RCSPs comprise a promising construction system for regions of moderate and high seismicity (Bournas et al. 2012). Ricci et al. (2013) performed, pseudo-static cyclic tests on real scale $(3.0 \mathrm{~m}$ by $3.0 \mathrm{~m})$ sandwich $\mathrm{R} / \mathrm{C}$ panels, with and without opening. It was concluded that the initial stiffness is consistent with the theoretical stiffness calculated considering an initial cracked cross section. The maximum strength increases with the applied axial load. The tested panels are able to withstand high horizontal loads which roughly corresponds to the elastic seismic base shear of midrise residential buildings. Paulay et al. (1982) tested squat shear walls subjected to seismic loading established that it is possible to ensure a predominantly flexural response involving considerable yielding of the flexural reinforcement. One prerequisite for flexural response and hence, for significant energy dissipation by plastic hinging, is suppression of shear failure by diagonal tension or compression. This can be achieved when the wall's shear strength is at least equal to shear demand imposed when flexural over strength of the wall is developed. Sliding shear along the base is the most significant cause of loss of stiffness and strength and consequent reduction in ability to dissipate energy for the desired hysteretic damping in squat shear walls. Unless specially detailed or subjected to high axial loading, all squat shear walls are likely to fail in this mode. Thomas et al. (1999) studied experimentally to understand the behavior of squat RC walls subjected to high cyclic shear. All specimens tested failed in a predominantly flexural mode, characterized by concrete crushing and reinforcement buckling at the confined edges. Moderate diagonal cracking of the web and sliding at the fixed base were also observed. Pinching of the hysteresis loops caused by horizontal sliding and bond-slip of vertical bars (rather than by shear crack opening) was significant in the conventionally reinforced specimens. 
Waiel et al. (2000) in their experimental study reveals that the lateral loads were increased to roughly ten times higher load levels than the design loads, only minor fine cracks have been observed on the surfaces. No important local failures have been detected. It was also interesting to observe that no separation have been occurred between two layers of each walls. Holden et al. (2003) conducted experiments on two types of precast concrete structural wall systems subjected to quasi-static reversed loading. The wall panel in this unit was embedded in a recess left in the foundation a distance equal to the development length in tension of the wall longitudinal reinforcement and then grouted. This unit showed excellent behavior in terms of the displacement capacity and energy dissipation. Another unit was part of a precast partially prestressed hybrid system that incorporated post-tensioned unbonded carbon fiber tendons, energy dissipators, and steel fiber reinforced concrete. Behaviour of 3D sandwich panels under simulated seismic loading through a large experimental campaign. The performance and failure mode of all panels tested revealed strong coupling between flexure and shear due to the squat type geometry of the panes. However due to their welldetailed reinforcement, all panels exhibited only a relatively gradual strength and stiffness degradation and in no case did any panel suffer from sudden shear failure. The prefabricated walls of the structural system investigated herein seem to meet all the requirements of Euro code 8 for walls to be designed as "large lightly reinforced walls"; however this assumption should be supported with further experimental and analytical studies (Rezaifer and Gholhaki, 2008). Dazio et al. (2009) tested RC walls under quasi-static cyclic loading. Experiments showed the reduced deformation capacity of RC structural walls with low longitudinal reinforcement content. This effect was further increased if reinforcing bars with low ductility properties were used. Selection of the structural system for precast concrete buildings and proper sound detailing is by far more important than sophistication in estimating seismic demand or in numerical analysis. It is not so much how the problem is analysed, but rather how the prefabricated structure is conceived and detailed. Connections should be carefully designed with view to continuity and structural integrity. Redundancy and structural integrity should be the basis of the design philosophy of earthquake resistant design of precast structures (Sauter, 1994)

\section{BEHAVIOUR OF 3D WALL PANEL UNDER OUTOF-PLANE LOADING (FLEXURAL)}

Gara et al. (2012) carried out experimental investigation on completed in-situ sandwich panels with non-shear connectors used as floor panels. As regards the flexural tests, single panels with different internal layer thickness and different lengths were tested. In all cases, the panels behaved as semi-composite elements, characterized by a low slip between the two concrete layers, thanks to the internal layer of the panels and the reinforced concrete beams at the ends of the panels. Simple analytical formulas to estimate the bending moments at cracking $\left(\mathrm{M}_{\mathrm{cr}}, \mathrm{d}\right)$ and at failure (MR, d) are proposed. However, low values of cracking and ultimate equivalent loads are obtained, especially for longer panels, since the restraint between wall and floor panels and the plate behaviour are both neglected in the tests. Precast sandwich slabs with $90^{\circ}$ steel connectors present a high deformability and a high degree of cracking even under normal service loads. Due to their low stiffness, the slabs with pinned support condition may reach their service limit state prior to reaching their ultimate limit state, thus leading to low utilization of the resistant capacity of the cross section. To increase their stiffness and to reduce the restrictions regarding the service limit state, it is important to design efficient reinforced connection between the slabs and their supporting element. The behaviour of all slabs tested is between the ideal behaviour of a full section and of independent layers, approaching slightly the latter. The overall contribution of the connectors to the flexural stiffness of the slabs is small (Carbonari et al. 2012). Kabir (2005) studied the structural properties of precast concrete sandwich panels under bending loads. The load deflection behavior shows that these panels carry the load as partially composite panels under service loads. In the linear elastic zone the stresses and strength of each panel can be computed by linear elastic structural analysis and the ACI code could be applied. For the non-linear portion, the section behaves as a precise, partially composite section and the analysis should be performed based on strain distribution.

Crack patterns in precast concrete sandwich slab panel were very similar to those in conventional solid slab as shown in Fig. 9. For all test specimens, first cracks occurred approximately at a load of 55-60\% of the ultimate load. Substantial degree of composite action was achieved by truss shaped shear connectors. All test specimens proved to be ductile, exhibiting large deformation prior to failure. Good correlation was found between results using finite element analysis and experimental obtained results. The ultimate strength and the degree of composite action desired to a large extent upon the stiffness of the shear connectors used (Benayoune et al. 2008).

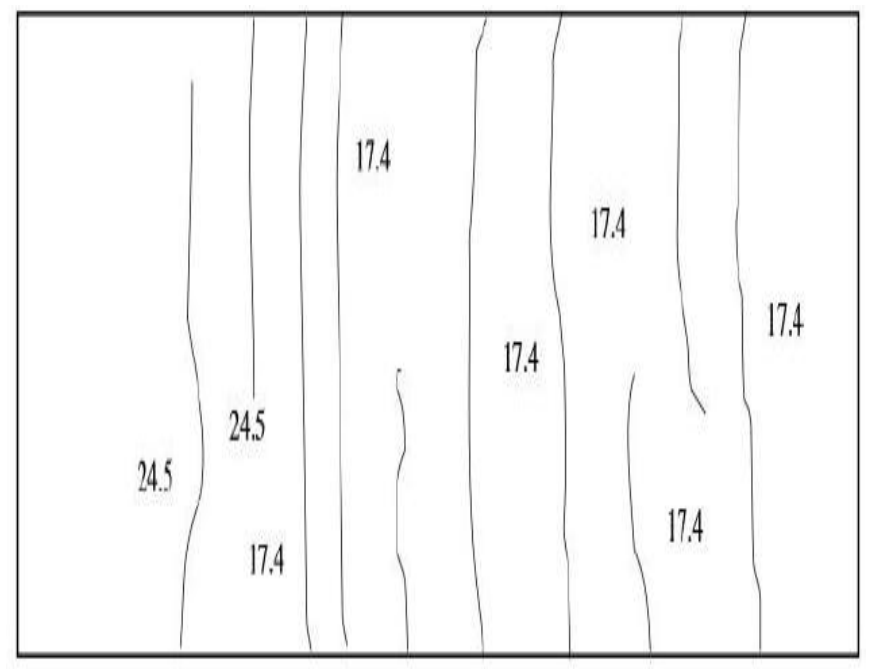

Fig. 9 Typical crack pattern for one-way slab specimenBottom wythe 
Flexural strength was increased with increasing the thickness of the panels, since panel stiffness increased with its thickness. The maximum central deflection was decreased when increasing the concrete strength of the outer wythes. Panels failed due to the separation of these wythes. The maximum slip was increased when increasing the concrete strength of the outer wythes (Waleed et al. 2013). Pessiki et al. (2003) in their experimental investigation, constructed a precast concrete sandwich wall panel similarly to the Prototype Panel treated in their study will behave as a fully composite panel in terms of service load-deflection behaviour and flexural strength. Panels with solid concrete regions placed intermittently along the span develop stress concentrations at the solid regions, do not exhibits plane section behaviour through the depth of the panels, and develop strains that are not uniform across the width of the panels. Early flexural cracking was observed for panels from the lateral load tests. Potential causes for this test, presence of initial cracks and an over estimation of the tensile strengths at cracking $4.0 \sqrt{ } \mathrm{f}_{\mathrm{c}}^{\mathrm{l}}$ for panel. The flexural strengths of the test panels were not obtained from the lateral load tests because the test panels were not loaded fully until they failed (Lee and Pessiki, 2008). Truss girders oriented in the longitudinal direction can provide ample shear transfer to achieve a high degree of composite flexural behaviour. This was possible since sufficient bond between the insulation and concrete wythe was maintained through ultimate. Test results indicated that due to the internal redundancy of the shear transfer mechanism, redistribution of shear can occur allowing the panel to continue resisting load. All panels tested proved to be very ductile, experiencing large deformations prior to failure (Bush and Stine, 1994).

\section{CONCLUSION}

This article gives an overview of the performance of $3 \mathrm{D}$ panels under general loading as load bearing construction. The literature on the 3D panel has been reviewed. From the literature, it is clear that the 3D panels are effective in load carrying capacity, shear capacity and flexural capacity. The axial compressive strength of wall panels, shear strength of wall panels in case of lateral loading application and flexural strength of slab panels are found to be suitable for economical, safety and eco-friendly building construction. Further these precast elements can be used as partition walls etc.

\section{REFERENCES}

[1] A Brief Introduction into the EVG-3D Panel Constrcuction System (Changing Construction Methods Worldwide)-report on 3D panel.

[2] Architectural Precast Concrete, Precast/ Prestressed Concrete Institute, Chicago, IL, 1989, p. 280-286.

[3] ASHRAE Handbook- Fundamentals, American Society of Heating, Refrigerating and AirConditioning Engineers, Inc., New York, NY, 1985.

[4] Benayoune, A., Abdul Samad, A.A., Trikha, D.N., Abang Ali, Akhand, A.M., 2004. Precast reinforced concrete sandwich panel as an industrialised building system, International Conference On Concrete engineering and Technology University Malaya, p. 1-6.

[5] Benayoune, A., Abdul Samad, A.A., Trikha, D.N., Abang Ali, A.A., Ellinna, S.H.M., 2008. Flexural behaviour of pre-cast concrete sandwich composite panel- Experimental and theoretical investigations. Construction and Building Materials Elsevier 22, p. 580-592.

[6] Benayoune, A., Abdul Samad, A.A., Trikha, D.N., Abang Ali, A.A., Ashrabove, A.A., 2006. Structural behaviour of eccentrically loaded precast sandwich panels. Construction and Building Materials Elsevier 20, p. 713-724.

[7] Benayoune, A., Abdul Samad, Ali, A.A., Trikha, D.N., 2007. Response of pre-cast reinforced composite sandwich panels to axial loading. Construction and Building Materials Elsevier 21, p. 677-685.

[8] Bournas, D.A., Torrisi, G., Crisafulli, F., Pavese, A., 2012. Experimental Investigation and Analytical Modeling of

[9] Prefabricated Reinforced Concrete Sandwich Panels. 15 WCEE, p. 1-9.

[10] Bush, T.D., Stine, G.L., 1994. Flexural Behaviour of Composite Precast Sandwich Panels with Continuous Truss Connectors. PCI Journal, p. 112121.

[11] Bush, T.D., Zhiqi, Wu., 1998. Flexural analysis of precast concrete sandwich panels with truss connectors. PCI Journal 43(5), p. 76-86.

[12] Carbonari, G., Cavalaro, S.H.P., Cansario, M.M., Aguado, A., 2012. Flexural behaviour of lightweight sandwich panels composed by concrete and EPS. Conctruction and Building materials Elsevier 35, p. 792-799.

[13] Carbonari, G., Cavalaro, S. H. P., Cansario, M. M., Aguado, A., 2013. Experimental and analytical study about the compressive behavior of eps sandwich panels. Materials Construction 63(311), p. 393-402.

[14] Dazio, A., Bayer, K., Bachmann, H., 2009. Quasistatic cyclic tests and plastic hinge analysis of RC structural walls. Engineering structures Elsevier 31, p. 1556-1571.

[15] Derecho, A.T., Ghosh, S.K., Iqbal, M., Fintel, M., 1979. Strength, Stiffness, and Ductility Required in Reinforced Concrete Structural Walls for Earthquake Resistance. ACI Journal 76-37, p. 875896.

[16] Einea, A., Salmon, D.C., Fogarasi, G.J., Culp, T.D., Tadros, M.K., 1991. State-of the-Art of Precast Concrete Sandwich Panels. PCI Journal 36(6), p. 7898.

[17] Farah Nora, A.A.A., Ali, A.A.A., Jaafar, M.S., Samad, A.A.A., Trikha, D.N., 2004. Ultimate Strength of Precast Concrete Sandwich Panel with Opening Under Axial Load. Journal - The Institution of Engineers, Malaysia 65(1/2), p. 8-12. 
[18] Fragomeni, S., Mendis, P.A., Grayson, W.R., 1994. Review of Reinforced Concrete Wall Design Formulas. ACI Structural Journal 91-S50, p. 521528.

[19] Fragomeni, S., Doh, J.H., Lee, D.J., 2012. Behavior of Axially Loaded Concrete Wall Panels with Openings: An Experimental Study. Advances in Structural Engineering 15(8), p. 1345-1358.

[20] Frankl, B.A., Lucier, G.W., Hassan, T.K., Rizkalla, S.H., 2011. Behavior of precast, prestressed concrete sandwich wall panels reinforced with CFRP shear grid. PCI Journal, p. 42-54.

[21] Franz Sauter, F., 1984. Earthquake Resistant Criteria for Precast Concrete Structures. Proceedings of the Eighth World Conference on Earthquake Engineering San Francisco, California, p. 629-636.

[22] Gara, F., Ragni, Laura., Roia, D., Dezi, L., 2012. Experimental behaviour and numerical analysis of floor sandwich panels. Engineering structures Elsevier 36, p. 258-269.

[23] Gara, F., Rangi, L., Roia, D., Dezi, L., 2012. Experimental tests and numerical modelling of wall sandwich panels. Engineering Structures Elsevier 37, p. 193-204.

[24] Garold, D., Oberlender.,. Everard, N.J., 1977. Investigation of Reinforced Concrete Walls. ACI journal 74(28), p. 256-263.

[25] Holden, T., Restrepo, Jose., Mander, J.B., 2003. Seismic Performance of Precast Reinforced and Prestressed Concrete Walls. Journal of Structural Engineering ASCE 129, p.286-296.

[26] Insteel Construction Systems, Inc., Brunswick, GA, Product Information Literature.

[27] Kabir, M.Z., 2005. Structural Performance of 3D Sandwich Panels Under Shear and Flexural Loading. Scientia Iranica 12(4), p. 402-408.

[28] Khare, R.K., Maniyar, M.M., Uma, S.R., Bidwai, V.B., 2011. Seismic performance and design of precast concrete building structures: an overview. Journal of Structural Engineering 38(3), p. 272-284.

[29] Kripanarayanan, K.M., 1977. Interesting Aspects of the Empirical Wall Design Equation. ACI Journal 74(20), p. 204-207.

[30] Leabu, V.F., 1959. Problems and Performance of Precast Concrete Wall Panels. Journal of the American Concrete Institute 56(20), p. 287-298.

[31] Lee, B., Pessiki, S., 2008. Experimental Evaluation of Precast, Prestressed Concrete, Three-Wythe Sandwich Wall Panels. PCI Journal 53(2), p. 95115.

[32] Madina Sahed, S., Prakash, D., 1990. Ultimate Strength f RC Wall Panels With Openings. Journal of Structural Engineering ASCE 116, p. 1565-1577.

[33] Madina Sahed, S., Prakash, D., 1989. Ultimate strength of RC wall panels in one-way in-plane action. Journal of Structural Engineering ASCE 115, p. 2617-2630.

[34] Manual for Structural Design of Architectural Precast Concrete, Precast/Prestressed Concrete Instiute, Chicago, IL, 1977, Chapter 6, p. 1-15.
[35] Mohamad, N., Omar, W., Abdullah, Redzuan., 2011. Precast Lightweight Foamed Concrete Sandwich Panel (PLFP) Tested Under Axial Load: Preliminary Results. Advanced Materials Research, Trans Tech Publications, Switzerland 250(253),p. 1153-1162.

[36] Nor Hayati binti Abdul Hamid., 2008. Seismic Performance of Monolithic Wall Panel subjected to Quasi-static Lateral cyclic loading. Journal - The Institution of Engineers, Malaysia 69(3), p. 10-17.

[37] Pavese, A., Bournas, D.A., 2011. Experimental assessment of the seismic performance of a prefabricated concrete structural wall system. Engineering Structures Elsevier 33, p. 2049-2062.

[38] Paulay, T., Priestley, M.J.N., Synge, A.J., 1982. Ductility in Earthquake Resisting Squat Shear walls. ACI Journal 79(26), p. 257-269.

[39] PCI Design Handbook-Precast and Prestressed Concrete, Third Edition, Precast/ Presressed Concrete Institute, Chicago, IL, 1985, Chapter 9, 55(61), p. 2-22.

[40] Pessiki, S., Alexandar, M., 2003. Experimental Evaluation of Composite Behavior of Precast Concrete Sandwich Wall Panels. PCI Journal 48(2), p. 54-71

[41] Rezaifar, O., Gholhaki, M., 2008. Nonlinear dynamic behaviour of structural frames constructed with 3D wall panels with Vertical Irregular arrangement. $1^{\text {st }}$ international conference on seismic retrofitting, Tabriz-Iran, p. 1-9.

[42] Ricci, I., Palermo, M., Gasparini, G., Silvestri, S., Trombetti, T., 2013. Results of pseudo-static tests with cyclic horizontal load on cast in situ sandwich squat concrete walls. Engineering Structures Elsevier 54, p. 131-149.

[43] Thomas, N.S., Kappos, A.J., Tegos, L.A., Penelis, G.G., 1999. Cyclic Load Behavior of LowSlenderness Reinforced Concrete Walls: Design Basis and Test Results. ACI Structural Journal 96(4), p. 649-661.

[44] Unnikrishna Pillai, S., Parthasarathy, C.V., 1977. Ultimate strength and design of concrete walls. Building and Environment Pergamon press 12, p. 25-29.

[45] Waiel, M., Faruk, K., Ercan, Y., Alper, I., Arda, B., 2000. 3D Behavior of Shotcreted Light Weight Panel Buildings. 12 WCEE, p. 1-7.

[46] Waryosh, W.A., Abtan, Y.G., Ali Dawood, M.H., 2013. Structural Behavior of Composite Sandwich Slab Panels. Journal of Engineering and Development 17(4), p. 220-232. 